\title{
An Assessment of Climate Change Impacts on Livelihood Patterns: A Case Study at Bakergonj Upazila, Barisal
}

\author{
Md. Rasel Sheikh*, Tania Akter \\ Department of Disaster Resilience and Engineering, Faculty of Disaster Management, Patuakhali Science and Technology University, Dumki, \\ Bangladesh
}

Email address:

raselsheikh55@gmail.com (Md. R. Sheikh), lunasannamat@gmail.com (T. Akter)

*Corresponding author

\section{To cite this article:}

Md. Rasel Sheikh, Tania Akter. An Assessment of Climate Change Impacts on Livelihood Patterns: A Case Study at Bakergonj Upazila, Barisal. Journal of Health and Environmental Research. Vol. 3, No. 3, 2017, pp. 42-50. doi: 10.11648/j.jher.20170303.11

Received: March 13, 2017; Accepted: April 21, 2017; Published: May 19, 2017

\begin{abstract}
Climate change is contemporary global threat to the whole world especially in the coastal area like Bangladesh. This study intends to assess the impacts of climate change in livelihoods at Bakergonj Upazila under Barisal district. Questioner survey, Focus Group Discussion (FGD), Key Informant Interview (KII) were used for information collection, cross validation and verifications with secondary sources of information. The study reveals that livelihoods (Farmer, Fisherman, day labor, rickshaw puller, employee, etc.) were seriously affected by natural hazardous events like flood, cyclone, storm surge, densely fog, heavy rainfall and etc. and climate change increase the intensity and frequency of hazards which impacts on people and their livelihoods and beyond what they cannot cope with this harmful situation by their limited capacities. Income level of community people had decreased, so people were separating from their traditional occupation, and they were seeking alternative profession. This study used Leopold matrix to clearly identify climate change impact on livelihoods which is affected by various hazards and it's seen in matrix that average impact value was 2.57483 above 5 , but individually farmer, day labor were mostly affected by hazard events. Among all hazards flood, cyclone, storm surge attack more frequently and creates disastrous situation. So, it thus calls for intervention by Government and NGOs to rescue the vulnerable community from climate change impacts.
\end{abstract}

Keywords: Climate Change, Hazard Event, Livelihoods, Community Capacity, Leopold Matrix

\section{Introduction}

Disasters is considered as one of the most serious threats to the world with its potential deleterious impact on human, material, economic, or environmental losses and sometimes huge impacts (e.g. SIDR) exceed the ability cope using its own resources (IPCC, 2001).

Bangladesh has been identified as one of the most vulnerable countries in the context of climate change (Huq 2001, Huq and Ayers 2008). Its exposure to frequent and extreme climatic events such as floods and cyclones (IPCC 2012) is a concern for policymakers and scientists. Over the years, successive governments, civil society organizations and development partners have come up with innovative approaches to help the affected people adapt to climate change (CC) (IPCC 2007).

Bangladesh is a disaster prone country which suffers from various natural disasters like cyclone, flood, storm surge, river bank erosion, drought, etc. (Rabbani, et al. 2013). CC adds a new dimension to its vulnerabilities to different disasters. It is now well recognized and accepted that $\mathrm{CC}$ will increase the frequencies and severities of different natural disasters. Different natural disasters cause widespread loss of lives, damage of properties, infrastructure and degrade the entire environment and disrupt the coastal ecosystem in the coastal Bangladesh (Ellis, 1998). Located on the Bay of Bengal with a flat and low-lying topography, Bangladesh is exposed to major storm and cyclones as well as flooding. Most of Bangladesh is less than $10 \mathrm{~m}$ above sea level, with almost $10 \%$ of the country below $1 \mathrm{~m}$. Between 1960 and 2002, Bangladesh experienced over 40 cyclones with up to half a million human casualties per event (Huq \& Khan, 2006)

$\mathrm{CC}$ is expected to increase the severity and frequency of weather-related natural hazards, such as storm surge, cyclone, high rainfalls, floods, droughts, salinity, soil degradation and erosion, extreme temperature, etc. posing a direct threat to 
livelihood and all sectors (Rahman, 2012). A combination of factors, including disasters, environmental changes, shortages and economic pressure, could increase the vulnerability of local people (Piguet, 2008). In effect, climate change works as a global phenomenon that makes existing social, economic, political, and environmental challenges even more serious at a local level (Crate and Nuttall, 2009).

The study mainly concentrates on identifying some noticeable hazards in the study area that affects livelihood pattern. In this study also identify existing livelihood pattern and ranked these according to their affected level. Hazard events are also ranked on the basis of their frequency and severity.

Climate change is emerging issue in the world, which is one of the greatest threats to environment conservation and living security. Increasing emission of greenhouse gases into atmosphere, human intervention to environment are further compounding this problem. Although the contribution of underdeveloped countries in climate change is minute, they are most vulnerable to climate change impact. Bangladesh's contribution to global greenhouse gas emission is only $0.025 \%$; it is among the most vulnerable countries to climate change. Bangladesh's atmospheric temperature is increasing at an alarming rate ( 0.06 degree Celsius per year).

Climate change is a burning issue in the world. Different scholars and organizations have defined climate change differently: according to Wikipedia the free encyclopedia "climate change is any long-term change in the statistics of weather over periods of the time that range from decades to millions of years". It can express itself as a change in the mean weather conditions, or in any other part of the statistical distribution of weather. Climate change may occur in specific region, or across the whole earth.

Ali (2012) argues that, Poor people are generally most vulnerable to climate change because they live in areas more prone to flooding, cyclones, droughts etc., and have little capacity to adapt to such shocks. They are also more dependent on ecosystem services and products for their livelihoods. Any impact that climate change has on natural systems therefore threatens the livelihoods, food intake and health of poor people. Loss of employment and impacts on assets are likely to reduce opportunities for education in several ways. During the natural disaster and post-disaster period children may be required to help more with household tasks leaving less time for schooling. Even catastrophic cyclone and storm surges damage school facilities and educational materials.

The study was designed considering some specific goals which are as follows:

1. To assess existing livelihood patterns in the study area

2. To find out climate change impacts on livelihoods

3. To develop a Leopold matrix to identify the impacts of hazardous event on livelihoods

\section{Methodology}

\subsection{Selection of the Study Area}

Bakergonj Upazila of Barisal is situated in southern part of
Bangladesh and it is near to coastal belt which is one of the worst affected Upazila by salinization, recurrent storm-cyclone and storm surge and many other climatic hazards events and especially the farmer's main livelihoodagriculture is seriously affected in year long.

\subsection{Primary Data Collection}

To estimate the existing hazards with their severity and influence on livelihood, the respondents were asked the common questions. The study was designed according to the community' perception where sample size was small. Here the average data were used which may reduce robustness of the study. The study was designed preferring qualitative description rather than quantitative data. However, data were rechecked and compared with established literature to maintain the rigor of the study. Primary data were collected through various methods such as-questionnaire survey, key information interview and focus group discussion.

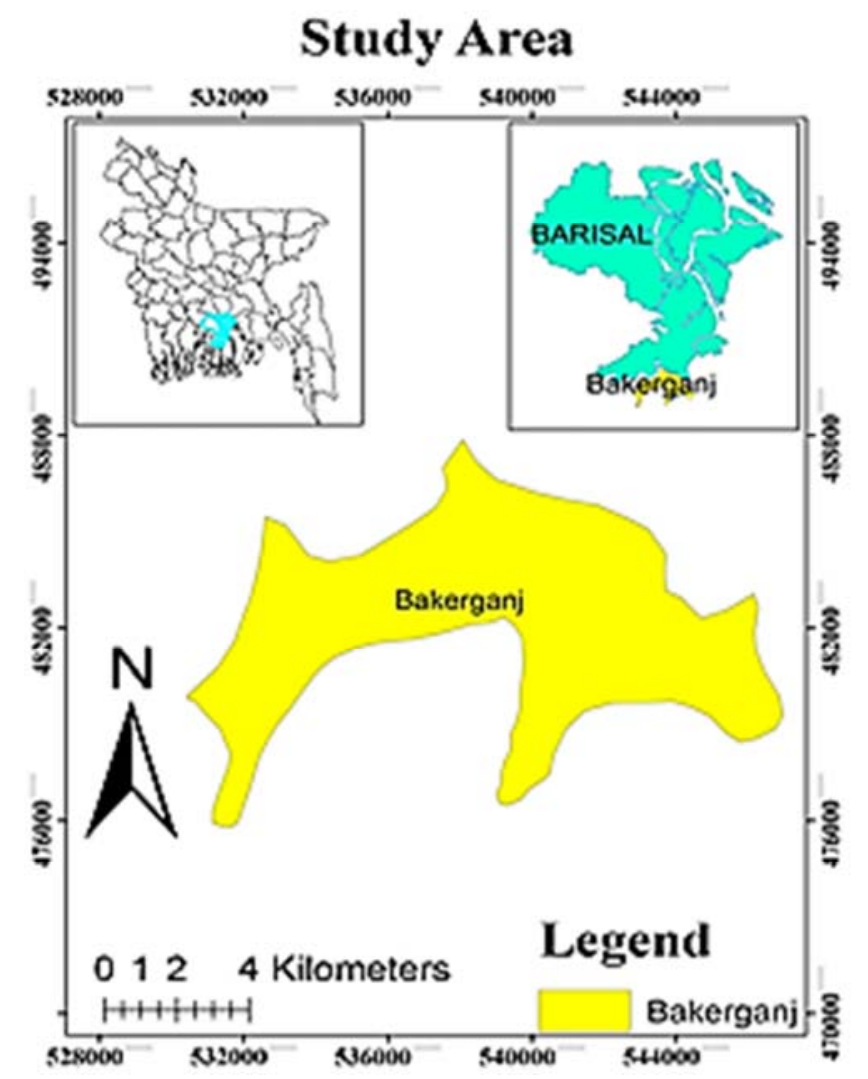

Figure 1. Map showing Physiography of the Study Area (Data Source: ArcGIS, 2014).

\subsubsection{Questionnaire Survey}

Data were collected through observations, structured questionnaires survey of the study area. The researcher requested to fill the questionnaire to the respective respondents. The respondents who were unable to fill up questionnaire, the questions were asked to the respondents and answers were filled up to collect the required data by the researcher. According to the schedule 90 interviews were taken following questionnaire to collect the information from 
selected unions. The selected community people were of mixed of all categories such as marginal, medium, rich and elite personnel. During data collection the following key queries problems were highly focused on existing climatic hazards and main disasters community face and their impact on local livelihood.

\subsubsection{Key Informants Interview}

The primary data were also collected from key informants using the direct or indirect interview method. The interview was taken as cross reference (checking) for the data obtained from the questionnaire. Key Informant Interviews (KII) were conducted from the Member of Union Parishasd in the study area, Upazila Agriculture officer, Upazila Fishery officer, Upazila Health and sanitation officer, Project manager of UTTARAN, Field officer of UTTARAN, community volunteer of UTTARAN. The informants were interviewed on the impact of climate change, impact on human health, impact on agriculture and overall impact on income level.

\subsubsection{Focus Group Discussion (FGD)}

FGD was designed to make-Hazard Calendar to identify the probability of occurring of hazards at different time of the year. Group discussion was carried out with 6-10 people and these members were selected from all level of livelihood. To identify the impact of climate change on livelihood patterns, FGD have been conducted in the study area by participation of the local community member including male and female members. In this meeting program people who attain the meeting frankly discuss about their climatic problem and all of these were note down in dairy.

\subsection{Secondary Data Collection}

The information were collected from different relevant scientific articles, reports, maps, journals, research paper, website, library, Bakergonj Upazila Agriculture Office and some local NGO offices etc. The information about the local crop cultivation practices; change in past and present cropping pattern related issues was gathered by cross matching among different sources.

\subsection{Data Analysis}

After the survey gathered date from completely filled up questionnaires, FGD, KII, secondary information's were processed and analyzed using Microsoft Excel computer software to make graphical representation and interpretations.

\section{Results and Discussions}

\subsection{Demographic Characteristic}

\subsubsection{Age Range}

All data were collected from Bakergonj Upazila by household questioner survey. According to questionnaire survey it has been seen that various age ranges of people were existed at Bakergonj Upazila. Among them 41\% people's age range was 29-39 yrs. and 31\% people's age range was 40-49 yrs. Figure 2 shows the range of age of the community people.

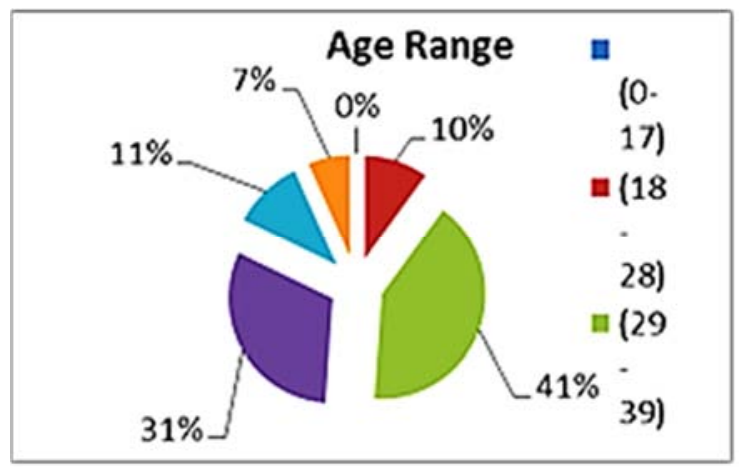

Figure 2. Range of Age of Community People.

\subsubsection{Gender Ratio}

Bakergonj Upazila is a over populated area of Barisal district. About $41 \%$ people were male and $59 \%$ were female in the study area were found by survey. During questioner survey in maximum household there was no male person in their house, so survey was completed by female person.

\section{Gender Ratio}

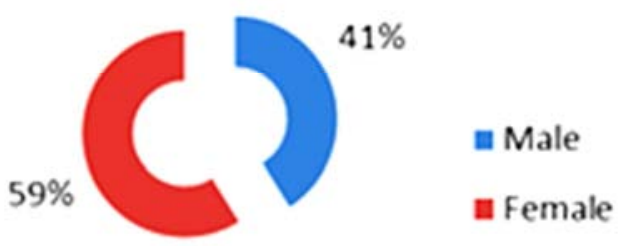

Figure 3. Gender ratio of the respondents.

\subsubsection{Educational Status}

In the study area near about $2 \%$ were illiterate, $7 \%$ were only sign, $39 \%$ people were primary educated, $30 \%$ were SSC passed, $8 \%$ were HSC passed and rest $4 \%$ people were BSc passed. Now-a-days people are so much careful about their future generation and they are trying hard and soul to educate their children. So their educational statuses are improving day by day. Figure 4 shows the educational status of the study area.

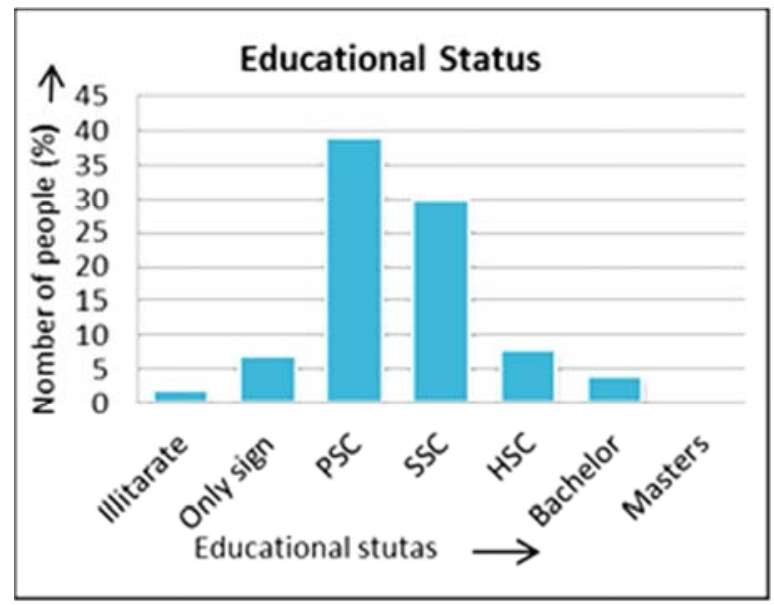

Figure 4. Educational Status of Bakergonj Upazila. 


\subsubsection{Profession}

According to questioner survey, more than half of the people were worked in household. Moreover, $12 \%$ people were farmer, $12 \%$ people were day labor, $9 \%$ people were different types of employee, and 5\% people have leaded their livelihood by doing small business. Some people were also fishermen, student, teacher, shopkeeper, rickshaw puller, and some people also doing any work in any time. And all of them were trying to fulfill their basic needs, but sometimes they were failed and sometimes they were successful to fulfill their basic needs.

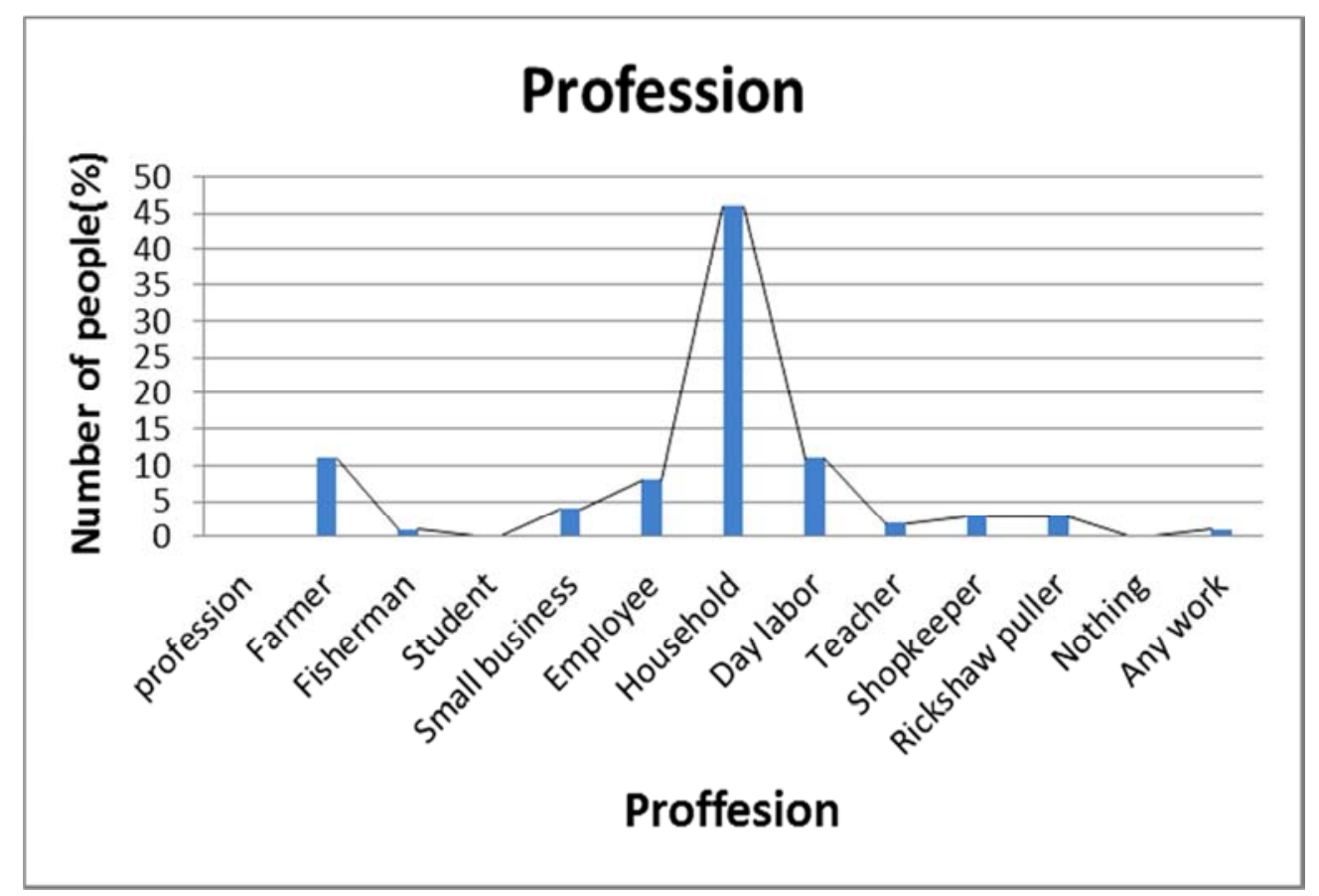

Figure 5. Profession of the People of Bakergonj Upazila.

\subsubsection{Income Level}

People at Bakergonj Upazila were not well developed and their income level were very low. Maximum people have no saving money in bank and they borrow loan from different bank and NGOs. In rainy season they do not have opportunity to work in the field and for this reason they take loan from money lender with high profit. About $42 \%$ people have income level between 2000-5000 taka, 36\% people's income were 5500-8000 taka, 8\% people's income were $8500-10000$ taka, $3 \%$ people's income were more than 10000 taka.

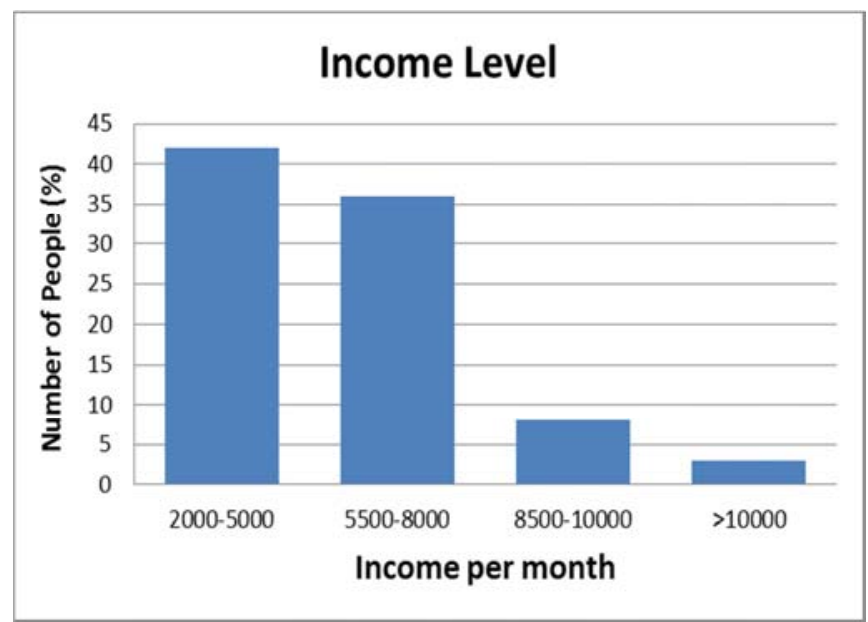

Figure 6. Income Chart of the People Bakergonj Upazila.

\subsection{Existing Livelihood Pattern}

Different livelihoods were subsists at Bakergonj Upazila. Among them farmer community, fisherman community, day labor, Rickshaw puller, businessman etc. were mostly important. More than $80 \%$ people were farmer, day labor, rickshaw puller which were exist in this area. The verification of existing livelihoods is shown in the figure 7.

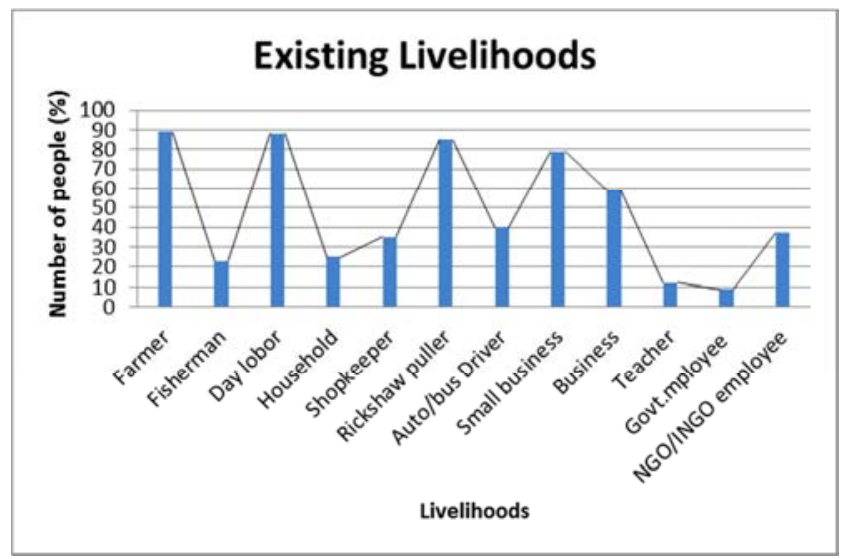

Figure 7. Existing Livelihood Options at Bakergonj Upazila.

\subsection{Livelihood Pattern Ranking}

Livelihood is the most importance aspect of community and the key concern for poor people in rural Bangladesh. CC creates huge negative impacts on livelihood patterns and it is 
badly effects on development. According to the field survey data CC impacts on livelihood patterns were ranked/priority and represented in the table 1. CC impacts on every livelihoods were noticed but farmer and day labor are mostly affected. In this study Priority Index Matrix was used to prioritize livelihoods and those were categorized as, highly severe $=5$, severe $=4$, moderate $=3$, minor $=2$, low $=1, \mathrm{No}=0$. Livelihoods ranking are shown at table 1.

\subsection{Existing Hazardous Event}

People at Bakergonj Upazila face various hazardous events in every year. $\mathrm{CC}$ increases the intensity and frequency of natural hazard and its effects on people's life, livelihood and property have been increasing day-by-day. According to people perception flood, cyclone, storm surge, heavy rainfall, extreme temperature and densely fog occurring most due to CC.

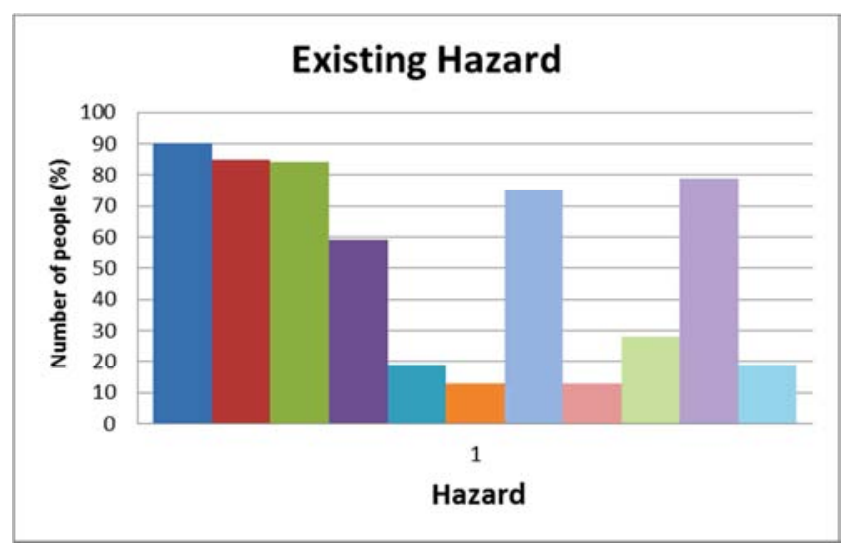

Figure 8. Hazard Existing at Bakergonj Upazila

\subsection{Hazard Event Ranking}

The effect of all hazard were not same, they were different from each other according to damage, loss and destruction. Bakergonj is mainly rural based area, so the poverty causes the great vulnerability for those hazard. Due to lack of data availability only eight types of hazard were found out in the study area. Each of the hazard have own charecteristics, intensity and frequency. According to peoples opinion all hazard were ranked on the basis of frequency and intensity. In Priority Index Matrix hazard were prioritized according to its frequency and intensity and those were categorized as, very high $=5$, high $=4$, medium $=3$, medium low $=2$, low $=1, \mathrm{No}=0$. Here, it has seen that flood is mostly occurring due to $\mathrm{CC}$ and all other types those were included here, occurring frequently due to $\mathrm{CC}$ and its impacts on people's life and livelihood were noticeable.

\subsection{Loss and Damage by Hazard}

Day to day climate is changing very rapidly, for this chainging global warming and green house gas effect is creating a great destrutive mood globally. As result of CC, our country is facing major hazardous situation adversely. According to Priority Index Matrix, damage and loss of hazard were categorized as, highly severe $=5$, severe $=4$, moderate $=3$, minor $=2$, low $=1, \mathrm{No}=0$. Flood and cyclone created more damage and loss than others. The estimation chart of loss and damage by different hazard according to local people perception is displayed in table 3 .

\subsection{Alternative Livelihood Options}

There were some alternative livelihoods found in this study area. More than 53\% people have gardening in homestead and non-homestead area, 31\% have rearing livestock like poultry farming, 5\% people were making handicraft, $3 \%$ people were busy in tailoring, $4 \%$ people have nursery, $1 \%$ people were migrated for seeking work and $3 \%$ people were doing other works.

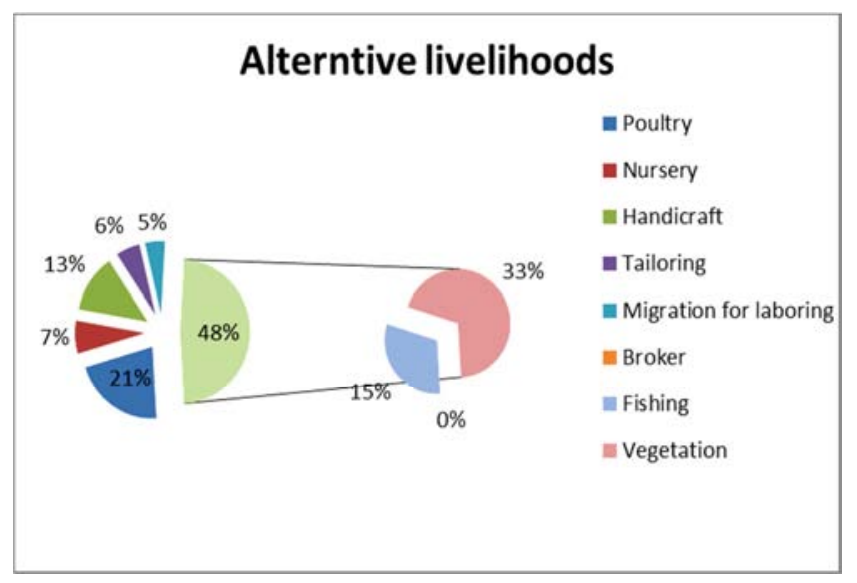

Figure 9. Alternative Livelihood Option at Bakergonj Upazila.

\subsection{Livelihood Seasonal Calendar}

People in study area have different livelihood patterns to lead their life. Their livelihood includes farmer, fisherman, day labor, shopkeeper, rickshaw puller, small business, large business, household worker and so one. Farmer works their field in whole year round, but sometimes in rainy season they do not work their field. Different hazards/disasters affect crops and vegetable and damage most of crops. During rainy season, fish production is more than other season. Day labors and rickshaw pullers were working in month of August to March, they also want to works in whole year but during rainy season they do not work their field. Small business and shopkeepers try to do their work in whole month, although various disasters affects their life and livelihood pattern. The livelihood seasonal calendar at Bakergonj Upazila is displayed in Table 4.

\subsection{Hazard Seasonal Calendar}

Hazards like natural and anthropogenic is a common phenomenon at the people living in Bakergonj Upazila. Every year they are experiencing various kinds of hazardous events and its effects creating negative impacts on life and livelihood patterns. The hazard events are flood, cyclone, storm surge, heavy rainfall, extreme temperature, hail storm, extreme cold, densely fog, short winter etc. Each hazard event occurs in any or some selected season of the year. 
According to community people's perception in study area, it is clear that, cyclone is mostly occurring in month of April to November. Similarly, flood is, another prominent hazard, occurring in month of May to September, storm surge in month of June to October as well. Heavy rainfall, extreme temperature, hail storm, drought, short winter, densely fog and extreme cold are another type of hazard shown in the seasonal calendar (Table 5).

\subsection{Impact of CC on Livelihood Pattern by Hazard Event}

$\mathrm{CC}$ creates various hazards event and these badly effect on livelihood patterns. The increase in frequency and intensity of natural disasters, i.e. floods and cyclones, has made it difficult for the local people to secure their livelihood. In addition to natural factors, several anthropogenic factors (e.g. electricity failure, high price of agricultural input, social barriers) remain the major form of vulnerability for the farmers, fishers and other livelihood sections of the society. The monsoon rainfall starts from Asher and normally lasts by Aswin in the study area. According to community people's perception, rainfall is increasing both in terms of amount and timing. Rainfall is ill-timed but increasing. The majority of the respondent replied that temperature has increased since few years. They felt summer are being hotter as before. In the fisheries sector climate change will have both negative and positive impacts. It appears that the impacts would not be remarkable in national context rather it would affect investment at individual level. The key expert's interviews and consultation workshops revealed that flood and cyclone affect fisheries severely while effects on other shocks such as drought, salinity intrusion, erratic rainfall, heat wave, cold wave, fogginess is low to moderate. This leads to loss of livelihoods of the poor fishermen and decrease nutrition status of the rural poor. Moreover, frequent warnings of cyclone lead the fishermen to stay at home for longer periods and thus their income decreased which increased their poverty level.

Here, Leopold matrix is used to identify the impact of hazard events on livelihood patterns. According to people perception of the study area, this matrix is drown. Impact factors have been evaluated separately for each hazard event and relevant livelihood pattern, and scored on a scale from 0 to 5 for impact magnitude, according to the following scale: 0 - no observable effect; 1 - low effect; 2 tolerable effect; 3 - medium high effect; 4 - high effect; 5 very high effect (devastation). From the Leopold matrix it can be said that, the impact of hazardous events on livelihood is tolerable.

\subsection{Adaptation Measures Adopted in Community}

People in study area are facing different climate changing situation and it hampering their income and production. The farmers have been adopting a variety of options and technologies to adapt to the impacts of climate change in agriculture. These measures include changing crop varieties, use of improved seeds of vegetables and food crops, changing cropping patterns, salinity resistant crops and vegetable, develop submergence crop, practicing intercropping system, terracing slopping lands to halt land slide and erosion, practicing the organic fertilizer to improve soil fertility instead of chemical fertilizers, irrigating vegetables and some crops with watering can. The fishermen has needed to improve their fishing technology, used engine boat for fishing and they must need to well- trained. The day labors and rickshaw puller are suffered most due to CC and its effects create adverse influences on their life and income. So, these type of essential alternate livelihood opportunity are needed to overcome disastrous situation. The shopkeepers and businessman should strongly construct their shop to protect different harmful situation. Housing plinth must be raise and if possible houses need to well-constructed building. Last of all, whole community people in study area need to educated and trained about their role and responsibility of pre-disaster, during-disaster and post disaster, and build resiliency and implement different adaptation and mitigation measures.

Table 1. Livelihoods Pattern Ranking.

\begin{tabular}{|c|c|c|c|c|c|c|c|c|c|}
\hline \multirow[b]{2}{*}{ Livelihoods } & \multicolumn{9}{|l|}{ Priority } \\
\hline & $\begin{array}{l}\text { Highly } \\
\text { Severe (5) }\end{array}$ & Severe (4) & Medium (3) & Minor (2) & Low (1) & No (0) & $\begin{array}{l}\text { Total } \\
\text { frequency }\end{array}$ & $\begin{array}{l}\text { Priority } \\
\text { index }\end{array}$ & Ranking \\
\hline Farmer & 39 & 28 & 21 & 02 & 0 & 0 & 90 & 4.15 & 02 \\
\hline Fisherman & 03 & 32 & 27 & 15 & 07 & 06 & 90 & 2.90 & 04 \\
\hline Day labor & 35 & 37 & 16 & 02 & 0 & 0 & 90 & 4.17 & 01 \\
\hline Household worker & 0 & 01 & 11 & 31 & 30 & 17 & 90 & 1.43 & 07 \\
\hline Rickshaw puller & 26 & 34 & 25 & 05 & 0 & 0 & 90 & 3.87 & 03 \\
\hline Shopkeeper & 01 & 01 & 29 & 45 & 14 & 0 & 90 & 2.22 & 06 \\
\hline Businessman & 01 & 09 & 33 & 28 & 17 & 02 & 90 & 2.81 & 05 \\
\hline Govt. employee & 0 & 0 & 0 & 19 & 37 & 34 & 90 & 0.83 & 10 \\
\hline NGO employee & 0 & 02 & 22 & 10 & 24 & 32 & 90 & 1.31 & 08 \\
\hline Others & 0 & 02 & 15 & 14 & 17 & 42 & 90 & 1.08 & 09 \\
\hline
\end{tabular}

(Source: Field Survey, 2016) 
Table 2. Ranking of Hazard Event at Bakergonj Upazila.

\begin{tabular}{llllllllll}
\hline \multirow{2}{*}{ Hazard } & \multicolumn{9}{l}{ Frequency and Intensity Priority } \\
\cline { 2 - 10 } & $\begin{array}{l}\text { Very } \\
\text { highly (5) }\end{array}$ & High (4) & Medium (3) & Minor (2) & Low (1) & No (0) & $\begin{array}{l}\text { Total } \\
\text { frequency }\end{array}$ & $\begin{array}{l}\text { Priority } \\
\text { index }\end{array}$ & Ranking \\
\hline Flood & 51 & 19 & 11 & 06 & 03 & 0 & 90 & 4.21 & 01 \\
Cyclone & 38 & 27 & 14 & 09 & 02 & 0 & 90 & 4.00 & 02 \\
Storm surge & 34 & 25 & 18 & 12 & 01 & 0 & 90 & 3.88 & 03 \\
Heavy rainfall & 17 & 28 & 21 & 07 & 05 & 12 & 90 & 3.24 & 04 \\
Extreme temperature & 13 & 31 & 23 & 12 & 06 & 05 & 90 & 3.10 & 05 \\
Extreme cold & 03 & 09 & 28 & 14 & 17 & 19 & 90 & 2.00 & 06 \\
Densely fog & 05 & 22 & 31 & 17 & 07 & 08 & 90 & 1.86 & 07 \\
Drought & 02 & 06 & 13 & 25 & 18 & 26 & 90 & 1.57 & 08 \\
High tide & 0 & 05 & 22 & 10 & 22 & 31 & 90 & 1.42 & 09 \\
\hline
\end{tabular}

(Source: Field Survey, 2016)

Table 3. Loss and Damage Priority of Hazard.

\begin{tabular}{llllllllll}
\hline \multirow{2}{*}{ Hazard } & \multicolumn{2}{l}{ Loss and damage priority } & & & & & Total \\
\cline { 2 - 9 } & $\begin{array}{l}\text { Highly } \\
\text { severe (5) }\end{array}$ & Severe (4) & Moderate (3) & Minor (2) & Low (1) & No (0) & $\begin{array}{l}\text { Priority } \\
\text { indequency }\end{array}$ & Ranking \\
\hline Flood & 54 & 21 & 09 & 06 & 0 & 0 & 90 & 4.36 & 01 \\
Cyclone & 39 & 35 & 08 & 07 & 1 & 0 & 90 & 4.16 & 02 \\
Storm surge & 30 & 32 & 15 & 13 & 1 & 0 & 90 & 3.89 & 03 \\
Heavy rainfall & 05 & 43 & 25 & 8 & 4 & 05 & 90 & 3.24 & 04 \\
Extreme temperature & 03 & 39 & 27 & 12 & 05 & 04 & 90 & 3.12 & 05 \\
Densely fog & 0 & 27 & 38 & 11 & 09 & 05 & 90 & 2.81 & 06 \\
Drought & 0 & 03 & 11 & 23 & 16 & 37 & 90 & 1.19 & 08 \\
High tide & 0 & 02 & 22 & 10 & 24 & 32 & 90 & 1.31 & 07 \\
Others & 0 & 0 & 08 & 09 & 12 & 61 & 90 & 0.06 & 09 \\
\hline
\end{tabular}

(Source: Field Survey, 2016)

Table 4. Livelihood Seasonal Calendar.

\begin{tabular}{|c|c|c|c|c|c|c|c|c|c|c|c|c|}
\hline \multirow{3}{*}{ Livelihood Types } & \multicolumn{12}{|c|}{ Seasons } \\
\hline & \multicolumn{4}{|c|}{ Summer } & \multicolumn{4}{|c|}{ Rainy } & \multicolumn{4}{|l|}{ Winter } \\
\hline & March & April & May & June & July & August & September & October & November & December & January & February \\
\hline \multicolumn{13}{|l|}{ Farmer } \\
\hline \multicolumn{13}{|l|}{ Fisherman } \\
\hline \multicolumn{13}{|l|}{ Day labor } \\
\hline \multicolumn{13}{|l|}{ Shopkeeper } \\
\hline \multicolumn{13}{|l|}{ Rickshaw puller } \\
\hline \multicolumn{13}{|l|}{ Small Business } \\
\hline Household worker & & & & & & & & & & & & \\
\hline
\end{tabular}

(Source: Field Survey, 2016)

Table 5. Hazard Seasonal Calendar at Bakergonj Upazila.

\begin{tabular}{|c|c|c|c|c|c|c|c|c|c|c|c|c|}
\hline \multirow{3}{*}{ Hazard Types } & \multicolumn{12}{|c|}{ Seasons } \\
\hline & \multicolumn{4}{|c|}{ Summer } & \multicolumn{4}{|c|}{ Rainy } & \multicolumn{4}{|l|}{ Winter } \\
\hline & March & April & May & June & July & August & September & October & November & December & January & February \\
\hline \multicolumn{13}{|l|}{ Cyclone } \\
\hline \multicolumn{13}{|l|}{ Flood } \\
\hline \multicolumn{13}{|l|}{ Strom Surge } \\
\hline \multicolumn{13}{|c|}{ Heavy Rainfall } \\
\hline \multicolumn{13}{|c|}{ Extreme temperature } \\
\hline \multicolumn{13}{|c|}{ Hail Storm } \\
\hline \multicolumn{13}{|l|}{ Drought } \\
\hline \multicolumn{13}{|l|}{ Short Winter } \\
\hline Extreme cold & & & & & & & & & & & & \\
\hline
\end{tabular}

(Source: Field Survey, 2016) 
Table 6. Leopold Matrix: Identification of Impact of Hazard Events on Livelihood Patterns.

\begin{tabular}{lllllllll}
\hline $\begin{array}{l}\text { Hazard event/Livelihood } \\
\text { pattern }\end{array}$ & Farmer & Fisherman & Day labor & House hold & Shopkeeper & $\begin{array}{l}\text { Rickshaw } \\
\text { puller }\end{array}$ & $\begin{array}{l}\text { Auto/bus } \\
\text { driver }\end{array}$ & $\begin{array}{l}\text { Small } \\
\text { business }\end{array}$ \\
\hline Flood & 5 & 3.1 & 4.7 & 3.8 & 3.7 & 4.7 & 3.8 & 3 \\
Cyclone & 4.9 & 5 & 5 & 4 & 3.9 & 5 & 4 & 3.3 \\
Storm surge & 5 & 4.5 & 4.7 & 3.5 & 3.4 & 4.9 & 3 & 3.5 \\
Heavy rainfall & 4.9 & 2.9 & 4.8 & 3 & 3 & 4.9 & 4 & 3 \\
Short winter & 3.6 & 0.2 & 1.5 & 0 & 0 & 0 & 0 & 0 \\
High tide & 4 & 0.3 & 0.9 & 3.3 & 0.8 & 1.4 & 0.8 & 1.3 \\
Extreme temperature & 4 & 3.6 & 4 & 2.2 & 2.1 & 3.2 & 3 & 2 \\
Extreme cold & 3 & 3.5 & 3.3 & 2.8 & 3 & 2.9 & 2 & 2 \\
Densely fog & 4.5 & 3.2 & 3.6 & 1 & 2.9 & 3.7 & 3 & 2 \\
Hail storm & 4.9 & 1 & 2.7 & 1.9 & 2 & 3 & 2.1 & 1.1 \\
Drought & 5 & 2 & 2.7 & 1.8 & 2.1 & 2.6 & 1.7 & 1.9 \\
Sum of value & 48.8 & 29.3 & 37.9 & 27.3 & 26.9 & 36.3 & 27.4 & 23.1 \\
Average value & 4.4364 & 2.664 & 3.445 & 2.482 & 2.445 & 3.3 & 2.491 \\
\hline
\end{tabular}

Table 6. Continued.

\begin{tabular}{|c|c|c|c|c|c|c|c|}
\hline $\begin{array}{l}\text { Hazard event/Livelihood } \\
\text { pattern }\end{array}$ & Business & Teacher & $\begin{array}{l}\text { Govt. } \\
\text { employee }\end{array}$ & $\begin{array}{l}\text { NGO/INGO } \\
\text { employee }\end{array}$ & Nursery & Sum of value & Average value \\
\hline Flood & 2.9 & 2.2 & 1.7 & 3 & 4.9 & 46.5 & 3.5769231 \\
\hline Cyclone & 3 & 2 & 1 & 3 & 3.3 & 47.4 & 3.6461538 \\
\hline Storm surge & 3.1 & 2 & 1.8 & 2.6 & 4.4 & 46.4 & 3.5692308 \\
\hline Heavy rainfall & 3 & 2.2 & 1.2 & 2.9 & 4.1 & 43.9 & 3.3769231 \\
\hline Short winter & 0 & 0 & 0 & 0 & 2.9 & 8.2 & 0.6307692 \\
\hline High tide & 0.8 & 1.1 & 0.8 & 3.2 & 3.5 & 22.2 & 1.7076923 \\
\hline Extreme temperature & 2 & 2 & 1.1 & 3.1 & 3.3 & 35.6 & 2.7384615 \\
\hline Extreme cold & 2 & 1.1 & 1 & 3 & 1.8 & 31.4 & 2.4153846 \\
\hline Densely fog & 2 & 1 & 1 & 2 & 3 & 32.9 & 2.5307692 \\
\hline Hail storm & 1 & 0 & 0 & 2 & 3.8 & 25.5 & 1.9615385 \\
\hline Drought & 2.1 & 0 & 0 & 1.8 & 3 & 26.7 & 2.0538462 \\
\hline Sum of value & 21.9 & 13.6 & 9.6 & 26.6 & 38 & & \\
\hline Average value & 1.9909 & 1.236364 & 0.873 & 2.418 & 3.455 & & 2.5643357 \\
\hline
\end{tabular}

(Source: Field Survey, 2016)

\section{Conclusions}

This study revealed that people at Bakergonj Upazila have faced various disastrous situations in every year due to $\mathrm{CC}$ and this disaster impact created so much negative influence on livelihood patterns, so that people face various problems to lead their life with their basic needs. Different livelihoods like farmer, fisherman, day labor, businessman etc. have existed in study area and these are affected by climatic impact. To recover their harmful situation they must develop their alternate livelihood opportunity, but alternate livelihood options which remained present in study area are not so strong and professional to cope with all climate changing situation and its affection. In Leopold matrix, it is clearly identified all hazards and its effects on livelihoods and the average impact of CC on livelihood pattern is 2.57483 , which is tolerable effect, but for specific some livelihoods, it creates devastating situation for these livelihood. This matrix indicates that farmers are affected most due to $\mathrm{CC}$ by hazards, then day labor, nursery, rickshaw puller and others. Among all hazards, cyclone affects most and occurring most then flood, storm surge, heavy rainfall etc. and the community people are suffering from those hazard frequently. In rainy season, people cannot go outside for doing daily working activities. Climate induced disaster inspirations all the sectors of livelihood patterns which are important for human survivability and welfare like agriculture, water and sanitation, health care, education, communication and so on. People losing their agricultural crop, their housing are collapsed again and again, their livelihood options totally damaged by climatic event in frequent disasters. So, it can be conclude that, as result of climate change livelihood pattern are changing gradually in the Bakergonj area.

From people's perception, questionnaire survey, focus group discussion and personal observations the following recommendations are identified;

I. Alternative livelihood opportunity must be developed in this area for relief people's sorrow and increase development.

II. Cyclone shelters construction, new embankment construction, road construction, culvert/bridge construction, canal excavation, sluice gate establishment, market development, housing condition 
development should be required in study area to protect from various disaster.

III.Develop family wise food preservation system to recover emergency situation.

IV.Cultivated climate resilient vegetable and crops and also increase floating agriculture.

V. Awareness raising program and early warning system must be developed for disaster preparedness and establish school first aid team, school based safety plan, school disaster management team and train all of them.

\section{Acknowledgement}

The author is grateful to UTTARAN, Barisal for their financial support to carry out field survey.

\section{References}

[1] ALI, M. M. (2012) Impacts of Climate Change on Cropping Pattern in Coastal Region of Bangladesh: A Case Study of Sharankhola Upazila, Bagerhat. Ms. Thesis: Brac University: Bangladesh. p. 101-135.

[2] CRATE, S. A., \& NUTTALL, M. (2009) "Introduction: Anthropology and Climate Change" in Susan A. Crate and Mark Nutall (Eds.) Anthropology and Climate Change, Walnut Creek: Left Coast Press.

[3] ELLIS, F. (1998) Livelihood Strategies and Rural Livelihood Diversification. Journal of Development Studies, 35 (1), p. $1-35$.

[4] HUQ, S. (2001) Climate change and Bangladesh. Science 294, 1617.
[5] HUQ, S., \& AYERS, J. (2008) Streamlining adaptation to climate change into development projects at the national and local level. In European Parliament (Ed.), Financing climate change policies in developing.

[6] HUQ, S., \& KHAN, M. (2006) Equity in national adaptation programs of action. In N. Adger, J. Paavola, S. Huq, \& M. J. Mace (Ed.), Fairness in adaptation to climate change (pp. 131153). Cambridge: MIT Press.

[7] IPCC (2001) Intergovernmental Panel on Climate Change. Climate Change 2001: Impacts, Adaptation, and Vulnerability. Report edited by McCarthy J. J. et al., Contribution of Working Group II to the Third Assessment Report of the Intergovernmental Panel on Climate Change. Cambridge University Press, Cambridge, UK.

[8] IPCC (2007) Climate Change 2007: Impacts, Adaptation and Vulnerability. Contribution of Working Group II to the Fourth Assessment Report of the IPPC. Cambridge: Cambridge University Press. p. 869-883.

[9] IPCC (2012) Managing the Risks of Extreme Events and Disasters to Advance Climate Change Adaptation. A Special Report of Working Groups I and II of the Intergovernmental Panel on Climate Change, Cambridge, UK, and New York: Cambridge University Press.

[10] RABBANI, G., RAHMAN, A., \& MAINUDDIN, K. (2013) Salinity-induced loss and damage to farming households in coastal Bangladesh. International Journal on Global warming. 5 (4), p. 400-415.

[11] RAHMAN, M. M. (2012) Enhancement of Resilience of Coastal Community in Bangladesh through Crop Diversification in Adaptation to Climate Change Impacts. BRAC University: Bangladesh. p. 15-50.

[12] PIGUET, E. (2008) Climate Change and Forced Migration, New Issues in Refugee Research, Research Paper No. 153, Geneva: UNHCR. 